\title{
Bradycardiac Angina: Haemodynamic Aspects and Treatment*
}

\author{
P. B. S. FOWLER, D.M., F.R.C.P. ; H. IKRAM, M.B., M.R.C.P., M.R.C.P.ED. ; R. N. MAINI, M.B., M.R.C.P., M.R.C.P.ED. \\ A. R. MAKEY, M.S., F.R.C.S.; J. S. KIRKHAM, M.A., M.CHIR., F.R.C.S.
}

Brit. med. F., 1969, 1, 92-94

Cummary : A patient with a sinus bradycardia and $\checkmark$ angina is described who was unable to increase his heart rate on vigorous exercise by more than a few beats. His severe angina was attributed to the bradycardia. Atrial pacing of his heart abolished his angina and increased his exercise tolerance. Circulatory changes at rest, on exertion, and with atrial pacing are described. The cause of angina in this patient is discussed.

\section{Introduction}

Anginal pain can be the direct result of bradycardia due to transient heart block (Fowler, 1962). While doing exercise tests on patients with the appropriate symptoms to find further examples of bradycardiac angina associated with heart block, a second group of patients was discovered in whom there was a bradycardia at rest with no significant change in the rate on exertion. These patients, in whom exercise does not significantly ircrease the heart rate, may also present with anginal pain. We describe a patient in whom the pain was completely relieved by a pacemaker. Haemodynamic studies were made at rest, on exertion, and at varying rates of atrial pacing. Though angina as a symptom in bradycardia has been mentioned previously (Hewlett, 1907 ; Stokes, 1909 ; Cowan, 1939 ; Bouvrain et al., 1967 ; Silverman et al., 1968), it has only twice been recognized that the anginal pain can be the direct consequence of the slow heart rate (Froment et al., 1959 ; Fowler, 1962). This is the first haemodynamic study of this condition.

\section{Case Report}

The patient, an accountant, was aged 59 when first seen in July 1963. For six months he had suffered from retrosternal pain on exertion with a choking sensation in the throat. He often experienced a sensation of faintness with the pain. All the symptoms were quickly relieved by rest. He had previously led an active life and had been a keen cross-country runner. When 5 years old he had suffered from diphtheria and for the next two years had been advised to avoid sports. He had been rejected for life insurance in 1947 for reasons unknown to him. When he was seen in 1963 examination revealed a regular pulse of $44 / \mathrm{min}$., a blood pressure of 155/90, normal heart sounds, and a mid-systolic murmur in the left sternal border. The electrocardiogram (Fig. 1) showed a sinus bradycardia of $45 / \mathrm{min}$., left axis deviation, and no other abnormality. A chest $x$-ray film was normal. The haemoglobin was 15.5 g. $/ 100 \mathrm{ml}$., W.R. was negative. The serum cholesterol was $225 \mathrm{mg} . / 100 \mathrm{ml}$. Protein-bound iodine was $6.7 \mu \mathrm{g} . / 100 \mathrm{ml}$.

Radioiodine and $T_{3}$ resin uptake tests were in the normal range. Electrocardiographic exercise tests were performed on several occasions. Angina was provoked after a predictable amount of effort on each occasion, with minimal increase in the heart rate and no $\mathrm{S}-\mathrm{T}$ segment changes on the cardiogram. The effects of atropine, amyl nitrite, subcutaneous adrenaline, and long-acting isoprenaline were studied and a therapeutic trial of these drugs was made. None produced definite benefit. The symptoms progressed and by 1968 he was forced to live a semi-invalid life. When admitted to hospital in March 1968 angina was induced by his walking round the bed. Acceleration of the heart by temporary atrial pacing produced a marked improvement in his exercise capacity.

On 24 March a pacemaker set at $84 / \mathrm{min}$. was implanted in the right axilla. Recovery was uneventful and he was graduaiiy mobilized. Two weeks later he could climb 60 stairs in the hospital without angina or other symptoms.

Methods.-Arterial and venous pressures were recorded on a multichannel physiological recorder by means of Statham P23d strain gauges connected to intraluminal catheters in the appropriate vessels. Cardiac output was measured by the Fick method. 'The oxygen content of expired air was measured by a Godart Pulmo-analyser. The oxygen saturation of arterial and mixed venous blood was measured by a Kipp Haemoreflector. Oxygen uptake was estimated by a timed collection of expired air in a Douglas bag and subsequent analysis. Temporary atrial pacing was performed by means of a bipolar electrode catheter positioned in the right atrium. The catheter was connected to an external pacemaker unit which permitted rate and voltage to be varied. Pacing was established with 4 volts. Electrocardiographic and haemodynamic exercise studies were performed on a stationary bicycle with a constant load and by the Master two-step method. Permanent atrial pacing was achieved by means of a Devices-St. George's abdominal type of pacemaker with a fixed rate of $84 / \mathrm{min}$. and an output of 5 volts. 
Surgical Technique.-The right side of the heart was approached via a right anterolateral thoracotomy. The pericardium was opened anterior to the phrenic nerve. The $2 \mathrm{~cm}$. of naked wire at the apex of the insulated wire loop electrode was buried in the right atrium just anterior to the sinoatrial node with silk sutures. The electrode wire was led up through the second intercostal space anteriorly and into a pocket fashioned in the axillary fat. The pacemaker unit was connected to the electrode and placed in the axillary pocket, the two indifferent electrodes being also anchored in the axilla.

Heart Rate.-The resting heart rate declined from 44 to $35 / \mathrm{min}$. during the course of the five years that he was observed. All the resting cardiograms showed sinus rhythm. On the several occasions that effort tests were performed, to the point of angina, the heart rate accelerated to between 43 and $50 / \mathrm{min}$. The rhythm on these occasions was predominantly sinus, though nodal and ventricular extrasystoles occurred. Intravenous atropine $0.5 \mathrm{mg}$. resulted in a nodal rhythm at a rate of $52 / \mathrm{min}$. Angina occurred after 80 and 75 seconds of exercise on the stationary bicycle in two separate studies during his last admission. With atrial pacing at the rate of $80 / \mathrm{min}$. and with the same load he was able to exercise for seven minutes without angina. At this point the pacemaker failed and angina occurred immediately. On resumption of pacing the anginal pain was relieved within two beats. A repeat exercise study confirmed that the pain was experienced and relieved almost instantly with cessation and resumption of pacing (Fig. 2).

Arterial Blood Pressure.-Resting, supine blood pressure over the years varied between $215 / 90$ and $155 / 90$. The arterial pressure at the time of angina during exercise was $248 / 100$. The blood pressure at rest with atrial pacing at a rate of $80 / \mathrm{min}$. was $200 / 105$. On exercise during pacing at this rate it was $200 / 128$, changing immediately to 204/100 when pacing ceased and angina occurred.

Venous Pressure.-The mean central venous pressure was $5 \mathrm{~mm}$. $\mathrm{Hg}$ at rest, and declined progressively to $-5 \mathrm{~mm}$. $\mathrm{Hg}$ when the rate was increased to $95 / \mathrm{min}$. The presence of atrial activity was confirmed by normal "a," "c," and " $v$ " pulsations.

Cardiac Output.-The resting cardiac output averaged $3.21 . / \mathrm{min}$. The changes in resting cardiac output with increasing heart rate are shown in Fig. 3. At a rate of $60 / \mathrm{min}$. the cardiac output was

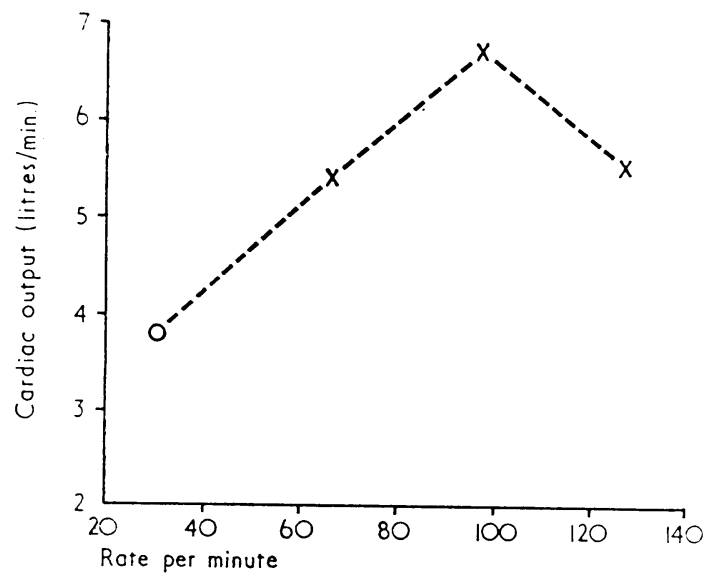

FIG. 3.-Alterations in cardfac output in response to varying rates of atrial pacing.

$5.5 \mathrm{l} . / \mathrm{min}$., at a rate of $95 / \mathrm{min}$. it was $6.8 \mathrm{l} . / \mathrm{min}$., and at $120 / \mathrm{min}$. it was $5.9 \mathrm{l} . / \mathrm{min}$. Exercise to the point of angina unpaced increased the output to $11.8 \mathrm{1} . / \mathrm{min}$. Exercise with the same load and atrial pacing at a rate of $80 / \mathrm{min}$. resulted in an output of $18.21 . / \mathrm{min}$.

\section{Discussion}

This case shows that angina can be caused by the inability to accelerate the heart in response to exercise. The increased heart rate caused a fall in venous pressure with a rise in cardiac output and arterial pressure. The relief of angina and improved exercise tolerance resulting from the increased heart rate provide further evidence of improved cardiac function. There was no evidence of coronary artery disease, as shown by a normal electrocardiogram at rest and lack of ischaemic changes on exertion. Furthermore, the relief of angina by speeding the heart emphasizes its different causation. It would appear that the cause of the persistent bradycardia in this patient was a primary degenerative disease affecting the sinoatrial node with no evidence of generalized muscle involvement. A similar degenerative aetiology has been suggested in complete heart block of the idiopathic variety (Smith and Zoob, 1961 ; Lev, 1964).

The mechanism of pain in this patient remains obscure. Coronary filling depends on a pressure gradient between the aorta and the coronary arteries during diastole. The latter is equivalent to the left ventricular diastolic pressure. In this patient the aortic diastolic pressure while exercising to the point of angina at his own rate was $20 \mathrm{~mm}$. $\mathrm{Hg}$ less than when the rate was doubled by pacing. This difference may be sufficient to cause impaired coronary filling and relative cardiac ischaemia during the period of increased metabolic demand caused by exercise. The absence of ischaemic changes on the cardiogram recorded during exercise is partly against this hypothesis. Coronary filling may be further impaired if there is a rise in the left ventricular diastolic pressure. This, by exerting pressure on the smaller coronary branches, will decrease coronary flow. It is known that, in people whose heart rate is relatively fixed, increase in cardiac output during exercise is achieved by an increase in stroke volume. In attaining this increase the heart may fill to a greater degree or empty more completely, or both (Rushmer, 1961), and a rise in diastolic pressure may result. This was not measured in our patient, since it was not considered justifiable to catheterize the left ventricle during exercise.

The observation that angina was produced within two beats of the cessation of pacing and instantly relieved by resumption (Fig. 2) suggests that a mechanical factor, such as stretching of the heart, may be responsible for the pain in this patient. This cause for anginal pain was first suggested by Merklen (1908). Accumulation of metabolites is unlikely to have been the cause of angina in view of the extreme rapidity of production and relief of the pain. It is well recognized that tachycardia can produce angina. This case illustrates that angina can also be caused by bradycardia. This is another group of patients in which angina can be cured. Changes in rate as well as in the $S-T$ segment should be noted during the exercise test in anginal subjects.

Those subjects with a persistent slow pulse during exercise need temporary pacing as a therapeutic test. If atrial pacing clearly shows relief of angina, permanent atrial pacing is indicated. Atrial pacing is easily achieved by implantation of a pacemaker at the sinoatrial node. This retains the haemodynamic benefits of atrial systole. This unusual method of cardiac pacing poses no special surgical problems.

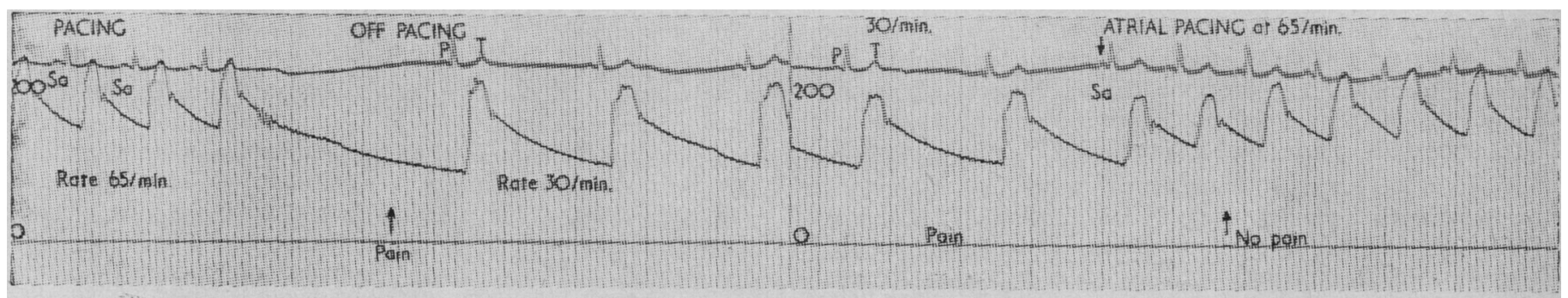

Fig. 2. - Changes in arterial blood pressure in response to pacing during an attack of angina. 
We wish to thank the Charing Cross Hospital Clinical Research Subcommittee for the gas-analysis equipment, and $\mathrm{Mr}$. P. Bosworth and Miss A. Smith for technical help and for mounting the tracings.

\section{REFERENCES}

Bouvrain, Y., Slama, R., and Temkine, J. (1967). Arch. Mal. Cœur, 60, 753.

Cowan, J. (1939). Brit. Heart F., 1, 3.
Froment, R, de Gevigney, D., Perrin, A., and Normand, J. (1959). Arch. Mal. Cour., 52, 481 .

Fowler, P. B. S. (1962). Brit. med. F., 2, 1638.

Hewlett, A. W. (1907). F. Amer. med. Ass., 48, 47.

Lev, M. (1964). Amer. 尹. Med., 37, 742.

Merklen, P. (1908). Leçons sur les Troubles Fonctionnels du Caur. Paris.

Rushmer, R. F. (1961). Cardiovascular Dynamics, 2nd ed. Philadelphia and London.

Stokes, K. H. (1909). Heart, 1, 297.
Smith, K. S., and Zoob, M. (1961). Brit. Heart f., 23, 458.

Smith, K. S., and Zoob, M. (1961). Brit. Heart f., 23, 458 . ${ }_{\text {Silverman, L. F., Mankin, H. T., and McGoon, D. C. (1968). 7. thorac. }}$ cardiovasc. Surg., 55, 264.

\section{Preliminary Communications}

\section{Maintenance of Encephalitogenic Viruses by Non-neuronal Cerebral Cells}

\author{
Brit. med.F., 1969, 1, 94-95
}

\begin{abstract}
Summary : Mouse and human brain glial elements have $\checkmark$ been successfully tissue-cultured and inoculated with two highly encephalitogenic viruses without apparent cytopathogenic effect but with long-term continued production of virus.
\end{abstract}

\section{INTRODUCTION}

The role of viruses in the pathogenesis of disease of the central nervous system (C.N.S.) is under intensive study at the moment. The ways in which viruses may affect the C.N.S. have been discussed by Webb and Smith (1966). The following experiments are of great interest, as they show how non-neuronal cells of whole mouse-brain tissue can support for a long time, without apparent damage, the multiplication of two arboviruses, Kyasanur Forest disease (K.F.D.) and Langat virus. These are both of group B tick-borne complex and are highly encephalitogenic to mice and sometimes human beings (Webb and Lakshmana Rao, 1961 ; Webb et al., 1966).

\section{Materials AND Methods}

Trypsin dispersed whole brain-cell suspensions were prepared from Swiss $A_{2} G$ white mice 3-6 days old. These cell suspensions were used at concentrations of $4 \times 10^{5} / \mathrm{ml}$. in Eagle's nutrient medium adjusted at $\mathrm{pH}$ 7.2. Each tube had a $1-\mathrm{ml}$. inoculum and was incubated at $37^{\circ} \mathrm{C}$. Langat virus was inoculated either at the time of seeding or after eight days of growth. K.F.D. virus was inoculated after eight days of growth.

Langat virus T.P.21 strain was used in its seventh mousebrain passage diluted in sterile saline containing $0.75 \%$ bovine albumin phosphate and buffered at $p \mathrm{H} 7$. Kyasanur Forest disease W3771 CD1V strain was used in its seventh mousebrain passage and diluted in the same way. Both viruses were received from Dr. C. E. Gordon Smith, Microbiological Research Establishment, Porton. Each virus was used at a dose of about 50,000 intracerebral mouse $\mathrm{LD}_{50}$.

Tubes of the viruses in Eagle's medium were also kept to see how long the virus remained active at the incubation temperature of $37^{\circ} \mathrm{C}$. Control tubes of mouse brain tissue culture were also kept in each experiment. All tubes of mouse brain tissue culture with and without virus were examined regularly, the medium being changed as necessary. When the medium needed renewing both test and control tubes were changed at the same time. At the time of changing the fluid suitable specimens were kept from each group of tubes and inoculated intracerebrally, $0.03 \mathrm{ml}$. into 3-4-week-old Swiss $\mathrm{A}_{2} \mathrm{G}$ mice. Parallel specimens were stored at $-60^{\circ} \mathrm{C}$. for further titration if necessary. If all the mice became typically paralysed around the sixth to seventh days from this neat fluid inoculation, further specimens were unfrozen and titrated in tenfold dilutions to estimate the total amount of virus present. Brains from the inoculated mice were kept so that the virus could be identified as that originally inoculated into the mouse brain tissue culture.

\section{RESULTS}

Mouse brain tissue culture cells have been kept growing successfully for 160 days on their own without subculture and with both viruses inoculated into them after eight days of growth. Langat virus has been released from these cells for 58 days. On the 44th post-inoculation day fluids from four out of six tubes had virus present. Three of these titred 3.0, 3.4 , and $2.3 \operatorname{logs}$ of virus respectively. On the 58 th day fluids from three tubes inoculated individually produced $2.4,2.5$, and $1.5 \operatorname{logs}$ of virus respectively. On the 65 th day fluids from three tubes were negative for virus, and to date no further virus has been isolated. K.F.D. virus was liberated from the cells up to the 51 st day, when a pool of three fluids gave 2.0 logs of virus. On the 37 th day a similar pool gave 2.3 logs. No virus was isolated from day 58 onwards. When Langat virus was inoculated at the time of seeding the results were very similar. Virus was still being liberated up to the 66th day, when four out of six fluids were positive, one titring 2.4 logs. Three tubes were negative on day 73 , but one out of three fluids was positive for virus on day 80 . Fluids from the tubes continue to be inoculated in case more virus is picked up at a later date. The other interesting feature has been that the cells in the infected tubes have appeared to multiply more rapidly than the controls. The viruses in the Eagle's medium survived for only 48 hours when used at the highest possible dose. Three points of interest arise from these findings:

(1) Neuronal damage is not a marked feature of encephalitis in immunologically mature mice inoculated with Langat virus intraperitoneally. It is much more pronounced the younger the mice and if the virus is given intracerebrally, when the death rate is $100 \%$ even after a very small dose. With large intraperitoneal doses of Langat virus in 6-8 week-old mice a small percentage have a clinical C.N.S. disturbance, but $100 \%$ show histological and virological evidence of encephalitis, the emphasis being on an inflammatory reaction (Webb et al., 